\title{
Dielectric Behaviour of PVA and Cornstarch Polymer Blend Electrolytes
}

\author{
M. Anandha Jothi, D. Vanitha, S. Asath Bahadur
}

\begin{abstract}
Simple film preparation method of solution casting has been used for making of biodegradable PVP and Cornstarch blend polymer electrolytes. Ion dynamics in polymer film membranes has been understood by conductivity and dielectric studies. The combination of 60wt\% PVA and 40wt\% Corn Starch is having the high conductivity value of $1.56 \times 10^{-9} \mathrm{~S} \mathrm{~cm}^{-1}$ at ambient temperature and when the temperature increases, the conductivity also linearly increases to obtain $4.93 \times 10^{-9} \mathrm{~S} \mathrm{~cm}^{-1}$ at $363 \mathrm{~K}$ which due to ion hopping mechanism in the polymer matrix. The frequency dependence of dielectric permittivity, dissipation factor (tangent loss) and electrical modulus have been used to know about dielectric behaviours of the polymer blend electrolytes. In dielectric studies, Non-Debye behaviour was observed in all samples.
\end{abstract}

Keywords: PVA, Cornstarch, Polymer blend, Conductivity and Dielectric studies.

\section{INTRODUCTION}

In recent times, polymer materials are plays significance role in sophisticated high energy electrochemical devices [1-4]. Poly (vinyl alcohol) (PVA) is soluble in water. It is the cheapest biodegradable polymer with excellent film forming capacity and it's containing semi crystalline nature $[5,6]$. Since decades ago, numerous endeavours have been centred on blending of natural polymers to prepare new materials with wanted properties. In this, corn starch is a natural, cheap copious and soluble in water [7-9]. Polymer blending is one of the techniques for developing the conductivity of electrolytes in electrochemical devices. Cornstarch is favored in light of the fact that it has the smallest particle size and furnishes better scatterings in blends with thermoplastic polymer. In this Cornstarch polymer composed of a mixture of linear amylase and branched amylopectin polysaccharide chain [10]. However, most of natural polymer such as Cornstarch formed very low thin film conductivity [11]. In efforts to overcome the disadvantages such as brittleness, many efforts are carried out to combine starch with synthetic polymers. In this work, conductivity, thermal and dielectric behavior of

Revised Manuscript Received on December 15, 2019.

* Correspondence Author

M. Anandha Jothi, Department of Physics, IRC, Multi Functional material laboratory, Kalasalingam Academy of Research and Education, Krishnankoil, Tamil Nadu, India. Email: anandhajothi.m@klu.ac.in

D. Vanitha*, Department of Physics, IRC, Multi Functional material laboratory, Kalasalingam Academy of Research and Education, Krishnankoil, Tamil Nadu, India. Email: vanibala2003@gmail.com

S. Asath Bahadur, Department of Physics, IRC, Condensed Matter Laboratory, Kalasalingam Academy of Research and Education, Krishnankoil, Tamil Nadu, India. Email: $\underline{\text { s_a bahadur@yahoo.co.in }}$
PVA: Cornstarch blend has been investigated.

\section{EXPERIMENTAL}

\section{A. Materials and Preparation method}

Polyvinyl alcohol and Corn starch with linear monomer formula of $\mathrm{C}_{2} \mathrm{H}_{4} \mathrm{O}$ and $\mathrm{C}_{6} \mathrm{H}_{10} \mathrm{O}_{5}$ were purchased from $\mathrm{Sd}$ finechem (SDFCL) and SRL chemicals (SISCO RESEARCH LABORATORIES PVT. LTD) respectively.

Different wt. \% of Cornstarch was dissolved in $50 \mathrm{ml}$ of double distilled (DD) water. The solution was heated at $75^{\circ} \mathrm{C}$ for 30 minutes in magnetic stirrer. Then the solution is cooled to room temperature. Later than various wt $\%$ of PVA were added to that solution under constant stirring. After 24 hours, the solution becomes homogeneous. The formed homogenous polymer blend solutions were transferred into Petri dishes and left to dry at ambient temperature for removal of solvent in the polymer membrane. Three days later, approximately $0.15 \mathrm{~mm}$ thickness of transparent polymer film was expelled from Petri dish for further analysis. All the polymer films were air tightly preserved under room temperature. The coding of the different composition of PVP and Cornstarch blend polymer electrolytes were as shown in Table I. The schematic image of preparation method was as shown in Fig 1.

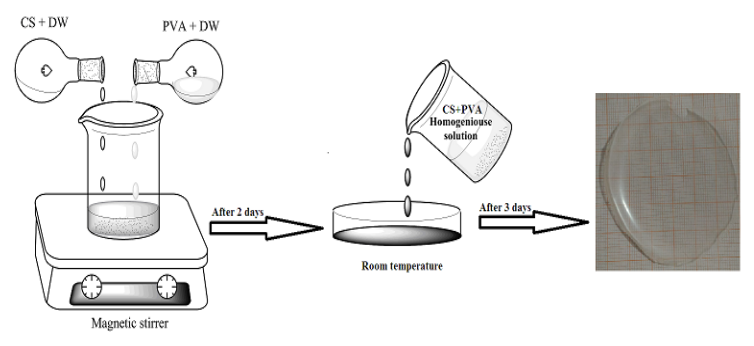

Fig. 1.Preparation method of polymer film

Table -I: Polymer film coding

\begin{tabular}{|c|c|}
\hline PVA: Cornstarch (wt. \%) & Film code \\
\hline $0: 100$ & VA-00 \\
$20: 80$ & VA-20 \\
$40: 60$ & VA-40 \\
$60: 40$ & VA-60 \\
$80: 20$ & VA- 80 \\
\hline
\end{tabular}




\section{B. Experimental technique}

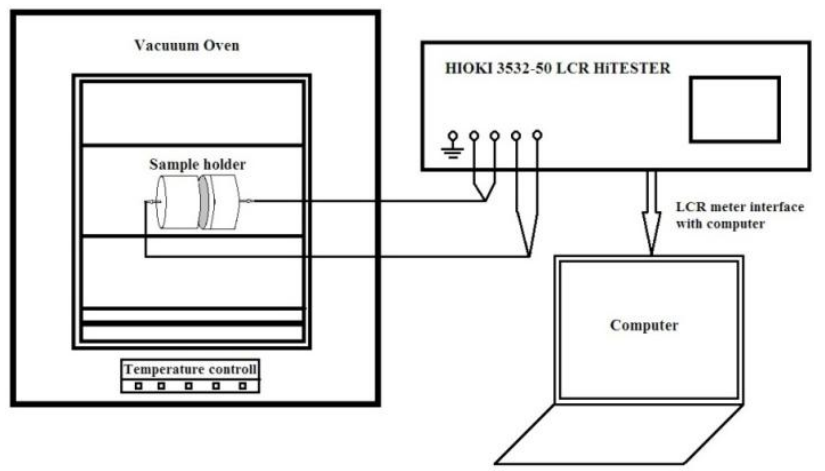

Fig. 2.Experimental setup of Conductivity and Dielectric studies

The conductivity and dielectric behaviour of the prepared polymer films were determined with help of HIOKI 3532-50 LCR over the frequency range of $42 \mathrm{~Hz}$ to $1000000 \mathrm{~Hz}$ at different temperature. Samples were mounted on the holder with silver electrodes (SE) under spring pressure with the configuration SE $\|$ SPE $\|$ SE. The ends of these two electrodes were connected to LCR meter and it was interfaced with computer for further analysis. Temperature dependent conductivity of the samples were carried out for $\mathrm{x}$ wt. $\%$ of PVA: $y$ wt. \% of Cornstarch ( $\mathrm{x}=0,20,40,60$ and 80 wt. \% \& $\mathrm{y}=100,80,60,40$ and 20 wt. \%) polymer blend membrane, under the same frequency and temperature various from ambient temperature to $363 \mathrm{~K}$.

\section{RESULTS AND DISCUSSION}

\section{A. Temperature dependent Conductivity / Composition dependence Conductivity at different Temperature}

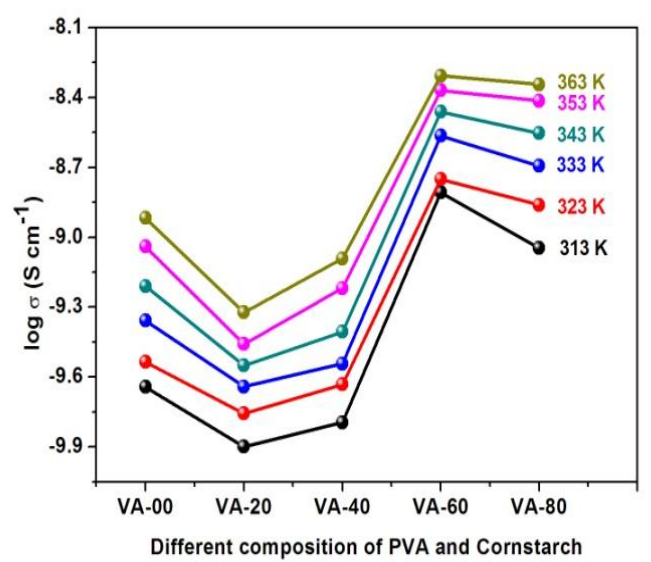

Fig. 3. Composition dependence conductivity of PVA: Cornstarch blend electrolytes at various temperatures

Fig 3 exemplifies the variation of conductivity as a function of different wt. \% composition of PVP and Cornstarch at different temperatures. The composition of VA-60 has reached the higher conductivity of $1.5 \times 10^{-9} \mathrm{~S} \mathrm{~cm}^{-1}$ at ambient temperature. The complete complexion of polymer blend is obtained for $60 \mathrm{wt}$. \% of PVP and $40 \mathrm{wt}$. \% of Cornstarch. The conductivity is increased due to the the easy movement of the mobile charge carriers. When rising the temperature, the conductivity of all the composition of polymer blends are linearly increases (Arrhenius behaviour) as clearly shown in Fig 3. Because of the polymer matrices have been expended to form the free volume and unoccupied spaces for migration of ions according to ion hopping mechanism [12]. Then the conductivity is increased to reach the value $4.93 \times 10^{-9} \mathrm{~S} \mathrm{~cm}^{-1}$ at $363 \mathrm{~K}$ for the same sample VA-60. This rise in conductivity values arises due to the increase in flexibility of the polymer electrolyte [13] and the inter- and intra chain hopping from chain bonding rotations and thereby increasing the number of density and mobility of ions [14].

Tabe- II: Conductivity and activation energy for all composition of PVA and Cornstarch

\begin{tabular}{|r|c|c|c|}
\hline \multirow{2}{*}{ Samples } & \multicolumn{2}{|c|}{$\boldsymbol{\sigma}(\mathbf{S} / \mathbf{c m})$} & \multirow{2}{*}{$\mathbf{E}_{\mathbf{a}}(\mathbf{e V})$} \\
\cline { 2 - 3 } & $\mathbf{3 0 3 ~ K}$ & $\mathbf{3 6 3 ~ K}$ & \\
\hline VA-00 & $2.3 \times 10^{-10}$ & $1.2 \times 10^{-9}$ & 0.32365 \\
VA-20 & $1.4 \times 10^{-10}$ & $4.8 \times 10^{-10}$ & 0.29897 \\
VA-40 & $1.8 \times 10^{-10}$ & $8.1 \times 10^{-10}$ & 0.24377 \\
VA-60 & $1.5 \times 10^{-9}$ & $4.9 \times 10^{-9}$ & 0.23175 \\
VA-80 & $6.7 \times 10^{-10}$ & $4.5 \times 10^{-9}$ & 0.3095 \\
\hline
\end{tabular}

\section{B. Arrhenius behaviour}

The temperature dependent conductivities of PVA-Cornstarch polymer electrolyte system investigated at temperature range of 313 to $363 \mathrm{~K}$ as shown in figure 4 . When the temperature increases from ambient temperature to higher temperature, the polymer matrices have been expended to form the free volume and unoccupied spaces for migration of ions. In this way conductivity of ions in PEs have been improved with increasing temperatures according to ion hopping mechanism. The conductivities are linearly increased by rising temperature in all the PE samples to obey the Arrhenius behaviour as shows in figure 4. Using linear fitting to the curves from log $\sigma$ versus $1000 / \mathrm{T}$ graph, then found the slope value from this plot. This slope value used for the calculation of activation energy $\mathrm{E}_{\mathrm{a}}$ for the PEs.

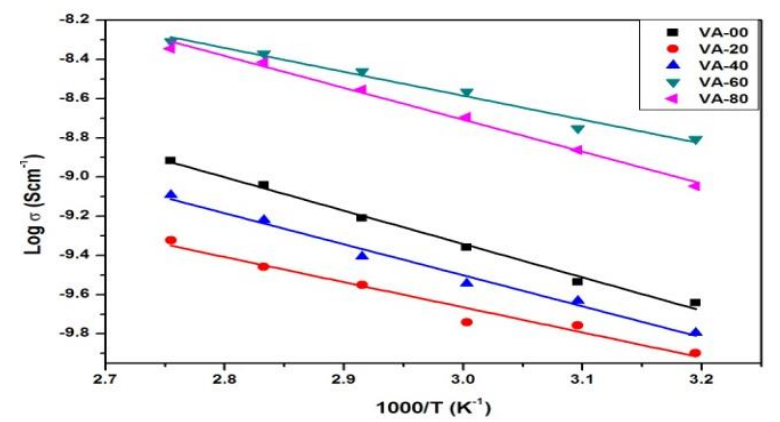

Fig. 4.Arrhenius plot for samples VA-00, VA-20, VA-40, VA-60 and VA-80

Activation energy $\mathrm{E}_{\mathrm{a}}$ was calculated using the Arrhenius rule, as given below

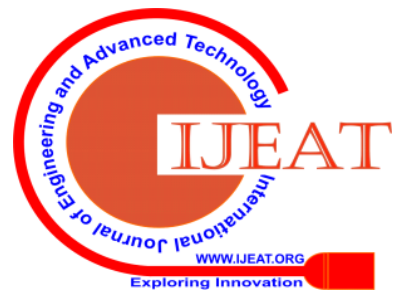


$\sigma(\mathrm{T})=\sigma_{\mathrm{o}} \exp \left(-\mathrm{E}_{\mathrm{a}} / \mathrm{KT}\right)$

where $\sigma(\mathrm{T})$ denote the temperature dependent conductivity ( $\mathrm{S}$ $\left.\mathrm{cm}^{-1}\right), \sigma_{\mathrm{o}}$ is the pre-exponential factor, $\mathrm{E}_{\mathrm{a}}$ is the activation energy $(\mathrm{eV}), \mathrm{K}$ is the Boltzmann constant $\left(\mathrm{J} \mathrm{K}^{-1}\right)$ and $\mathrm{T}$ is absolute temperature $(\mathrm{K})$.High conducting sample VA-60 has low activation energy of $0.23 \mathrm{eV}$.

\section{Dielectric Studies}

An examination on the dielectric behavior of the polymer electrolyte encourages us to comprehend the polarization impact at the electrode-electrolyte interface. The complex dielectric $\varepsilon *$ of a system is expressed as,

$$
\varepsilon *=\varepsilon_{\mathrm{r}}-\mathrm{i} \varepsilon_{\mathrm{i}}
$$

Where $\varepsilon_{\mathrm{r}}$ is a measure of the charge stored in the material, while $\varepsilon_{\mathrm{i}}$ corresponds to the amount of energy loss to move ions.

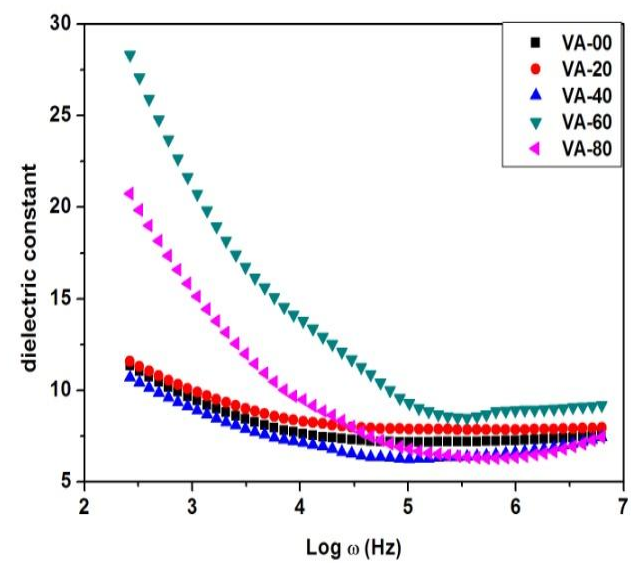

Fig.5a. Frequency dependence of dielectric constant $\left(\varepsilon_{\mathrm{r}}\right)$ for all composition of PVA: Cornstarch blend electrolytes at ambient temperature

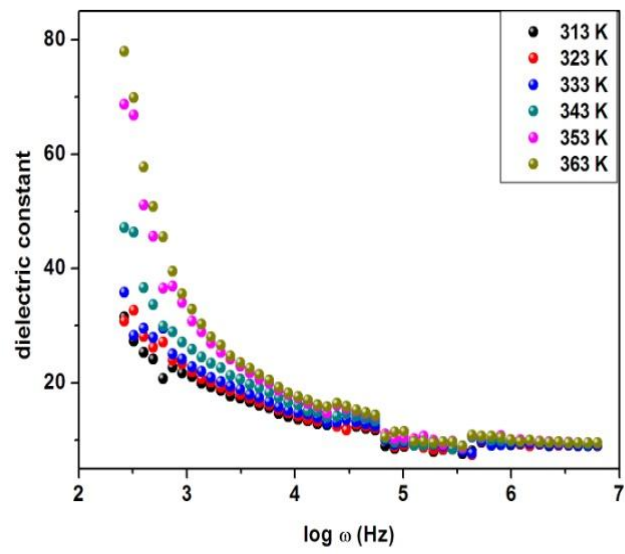

Fig.5b. Dielectric constant $\left(\varepsilon_{\mathrm{r}}\right)$ for VA-60 sample at different temperature all composition at ambient temperature

The equations for the dielectric constant $\varepsilon_{\mathrm{r}}$ and dielectric loss $\varepsilon_{\mathrm{i}}$ are shown as follows

$$
\begin{array}{r}
\varepsilon_{\mathrm{r}}=\mathrm{Z}_{\mathrm{i}} / \omega \mathrm{C}_{0}\left(\mathrm{Z}_{\mathrm{r}}^{2}+\mathrm{Z}_{\mathrm{i}}^{2}\right) \\
\text { and } \varepsilon_{\mathrm{i}}=\mathrm{Z}_{\mathrm{r}} / \omega \mathrm{C}_{0}\left(\mathrm{Z}_{\mathrm{r}}^{2}+\mathrm{Z}_{\mathrm{i}}^{2}\right)
\end{array}
$$

Where $Z_{\mathrm{i}}$ is an imaginary part of impedance $(\Omega), Z_{\mathrm{r}}$ is a real part of impedance $(\Omega), C_{0}$ is vacuum capacitance $(\mathrm{F})$ and $\omega$ is angular frequency $(\mathrm{Hz})$.

Fig. $5 \mathrm{a}$ and $5 \mathrm{~b}$ gives the variation of dielectric permittivity $\varepsilon_{\mathrm{r}}$ with respect to frequency at ambient temperature and different temperature respectively. Form the figure, it is confirmed that the dielectric constant decrease by increasing the frequency. The concentration ratio of PVA in the polymer blend matrices (VA-60) shows the high dielectric constant. Since, Composition dependence Conductivity result also replicate the same sample VA-60 has higher conductivity than other samples. At the low-frequency window, the dielectric constant is maximum which is due to the space charge polarization at electrode $\|$ electrolyte interface.

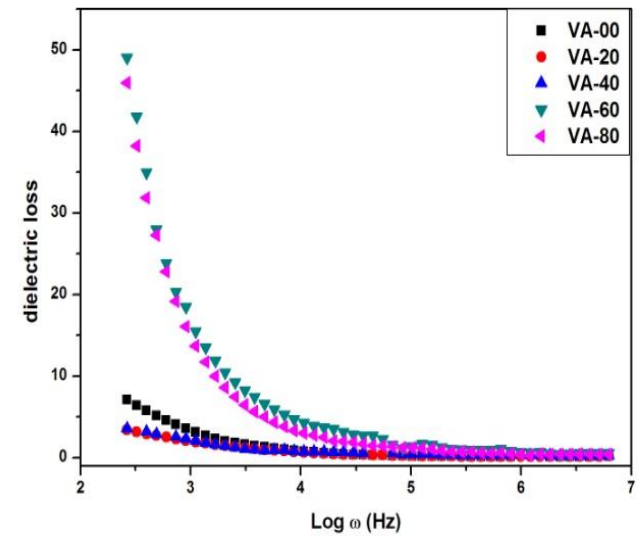

Fig. 6a. Frequency dependence of dielectric loss $\left(\varepsilon_{\mathrm{i}}\right)$ for all composition of PVA: Cornstarch blend electrolytes at ambient temperature

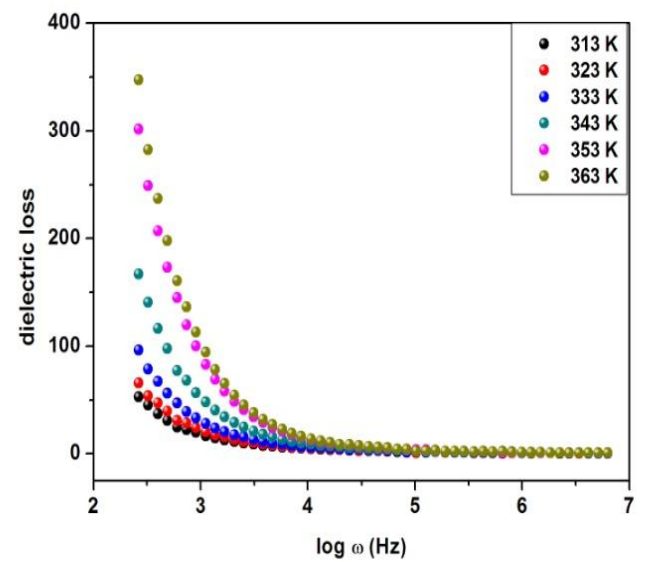

Fig. 6b. Dielectric loss $\left(\varepsilon_{\mathrm{i}}\right)$ for VA-60 sample at different temperature all composition at ambient temperature

For all the SPEs, the conduction path way is influenced by the number of charge carriers, the concentration of mobile ions and the availability of connecting polar domain [15].This nature also confirms the non-Debye dependence [16].The dielectric constant decreases for rest of the other concentration (VA-00, VA-20, VA-40). 
This is because of the aggregation of ions, leading to decrease in the number of mobile charge carriers and hence the mobility. The same behaviour is observed in Fig. 5b. When apply heat to the polymer membrane, it's become elongated to obey the free volume theory, increase the flexibility and also improve the amorphous nature. In this way the dielectric constant improved by applying of heat in the polymer membrane. So the dielectric constant of the higher conducting sample increases by rising of temperature. The same behaviour is observed for dielectric loss and it is shown in the fig. $6 \mathrm{a}$ and $6 \mathrm{~b}$. The dielectric loss reaches the saturation value at high frequencies because of the reduction of charge carriers at the boundary among electrode and electrolyte. The interrupted reversals of the electric field takes place quickly at high frequencies where there is a shortage of ion diffusion in the direction of the field [17]. The polarization is then decreased, leading to the decrease in the values of $\varepsilon_{\mathrm{r}}$ and $\varepsilon_{\mathrm{i}}$.

\section{Modulus studies}

The Modulus analysis is used to The display conductivity relaxation process and ion hopping mechanism in polymer electrolytes. The variation in the values of $\mathrm{M}^{\prime}$ and $\mathrm{M} /$ with frequency are portrayed in Figure $4 \mathrm{a}$ and $4 \mathrm{~b}$, separately.

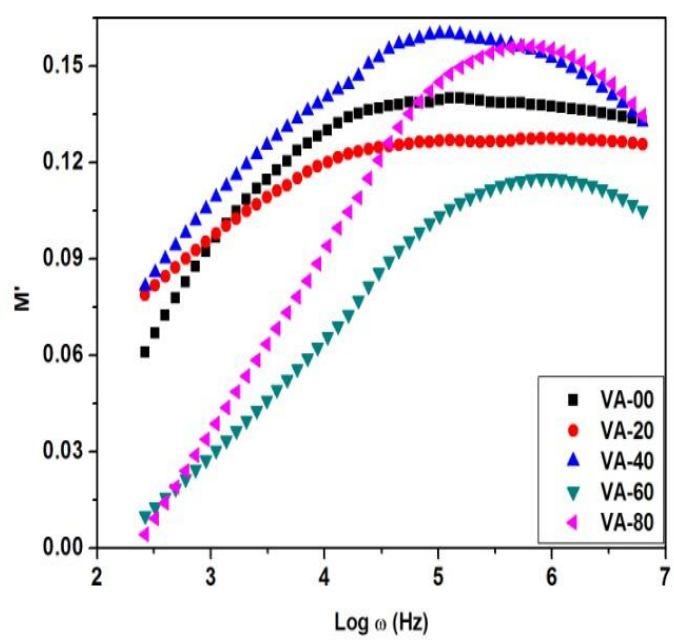

Fig. 7. Variation of the real part of the modulus $\left(\mathrm{M}^{\prime}\right)$ for all composition of PVA: Cornstarch blend electrolytes at ambient temperature

Fig 7 reveals the real part of the modulus $\left(M^{\prime}\right)$ for all composition of PVA: Cornstarch blend electrolytes at ambient temperature and different temperature of VA-60 sample respectively. At lower frequencies, the $M^{\prime}$ value approaches to zero for sample VA-60 and VA-80which is due to the negligible electrode polarization. The non -Debye behavior is confirmed by the long tail at low frequency region and the capacitance effect at the electrodes. [18, 19].

In imaginary part of electric modulus analysis $\mathrm{M}^{\prime \prime}$ there are two humps are appeared in VA-60 and VA-80 due to the semi crystalline nature of PVA and Cornstarch. At low frequency region, $\alpha$-crystalline and at high frequency region, $\beta$-amorphous regions are present in these two samples.

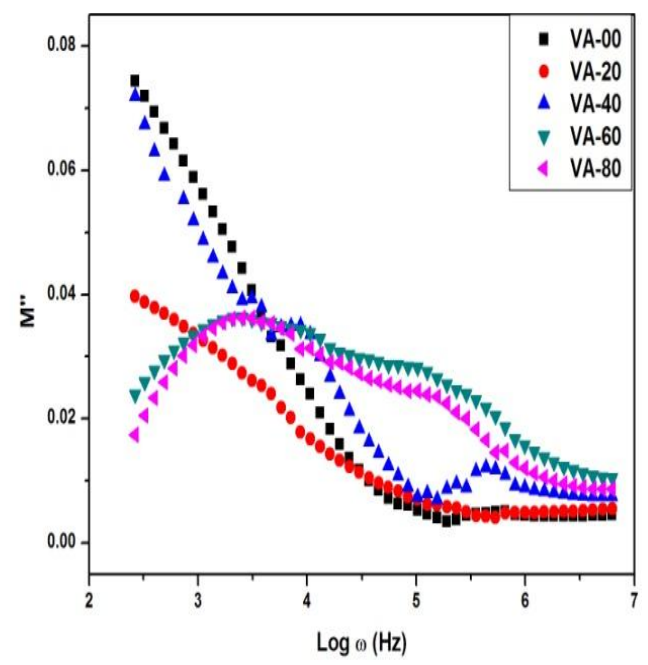

Fig. 8a. Variation of the imaginary part of the modulus $\left(M^{\prime \prime}\right)$ for all composition of PVA: Cornstarch blend electrolytes at ambient temperature

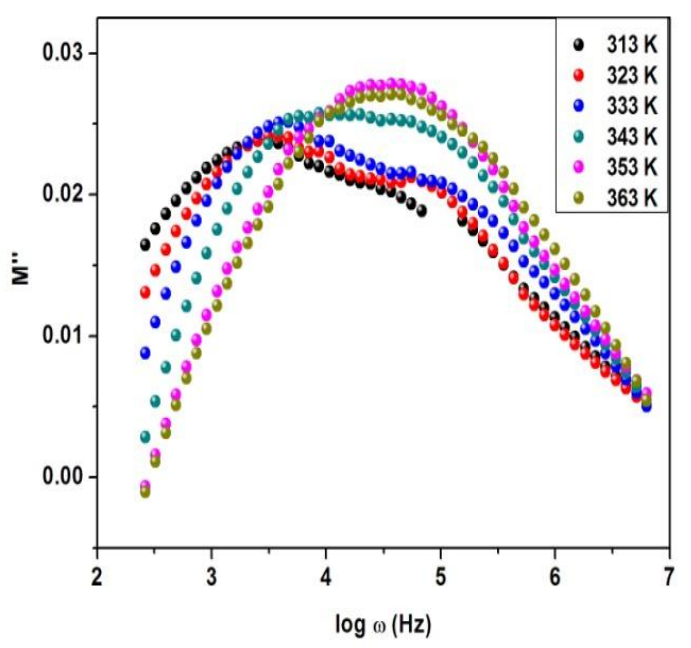

Fig. 8b. The imaginary part of the modulus $\left(\mathrm{M}^{\prime \prime}\right)$ for VA-60 sample at different temperature

From fig. 8a, two relaxation times $\tau_{1}$ and $\tau_{2}$ are observed. Thus, $\tau_{1}$ due to $\alpha$ relaxation peaks by dynamic dipole rotation and $\tau_{2}$ due to $\beta$ relaxation peaks by dipole orientation in static region respectively. Since, high conducting sample obtain low relaxation time. Improvement of amorphous nature in the polymer matrix by increase of temperature is clearly shown in Fig. 8b. When increase the temperature, two humps in $\alpha$-crystalline and $\beta$-amorphous regions of higher conducting sample VA-60 becomes merging to form a single hump and also shifted towards at high frequency region [20]. Since, the semi crystalline structure of the PVA: Cornstarch blend polymer electrolytes changes into the amorphous structure at high temperature. The electric modulus study is widely used to deduce the bulk dielectric behavior in case of the polymer electrolytes as a function of the frequency.

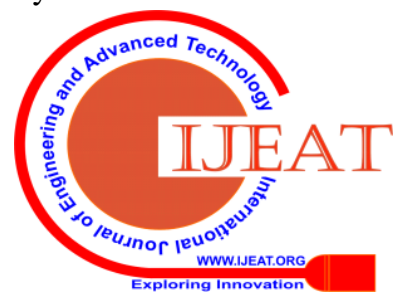




\section{CONCLUSION}

PVA and Cornstarch based blend polymer electrolytes using double distilled water as a solvent have been prepared by technique of solution casting. Conductivity, dielectric $\left(\varepsilon_{\mathrm{r}}\right.$, $\varepsilon_{i}, M^{\prime}$ and $M^{\prime \prime}$ ) and thermal behavior of polymer blend electrolytes have been analyzed in the frequency range of 42 $\mathrm{Hz}$ to $1000000 \mathrm{~Hz}$. The higher conductivity observed at ambient temperature and high temperature are found to be $1.56 \times 10^{-9} \mathrm{~S} \mathrm{~cm}^{-1}$ and $4.93 \times 10^{-9} \mathrm{~S} \mathrm{~cm}^{-1}$ for the composition of 60 wt. \% of PVA and 40 wt. \% of Cornstarch. The plot of composition dependence conductivity shows that all electrolytes obeyed the Arrhenius rule with thermally activated process. Dielectric constant and dielectric loss are increased by increasing the temperature for all the polymer blend electrolytes. When increasing the temperature, two humps in $\alpha$-crystalline and $\beta$-amorphous regions of higher conducting sample VA-60 becomes merging to form a single hump and also shifted towards at high frequency region. The modulus analysis reveals the change in the amorphous nature of the polymer blend at high temperature and denotes the thermally enacted relaxation process and shows the non-Debye nature.

\section{ACKNOWLEDGMENT}

Authors are thanked International Research centre (IRC), Kalasalingam Academy of Research and Education for Providing facilities and fellowships to carry out the research.

\section{REFERENCES}

1. B. L. Papke, D. F. Shriver, M. A. Ratner, M. Brodwin, R. Duppon and T. Wong, "Structure and ion transport in polymer-salt complexes," J. Solid State Ionics, vol. 5, pp. 83-88,October 1981.

2. M. B. Armand, "Polymer Electrolytes,"Ann.Rev.Mater.Sci., vol. 16, pp. 245-261, August 1986.

3. D. F. Shriver and M. A. Ratner, "Ion transport in solvent-free polymers," J. Chem.Rev., vol. 88, pp. 109-124, January 1988.

4. A. L. Laskar, J. R. Owen and S. Chandra, Superionic Solids and Solid Electrolytes - Recent Trends, Academic Press: New York, 1989.

5. J. Su, Z. Y. Ma, J. I. Scheinbeim and B. A. Newman "Ferroelectric and piezoelectric properties ofnylon 11/poly (vinylidene fuoride) bilaminate flms," J. Polym Sci Polym Phys, vol. 33, pp. 85-91, January 1995.

6. A. Tawansi and H. M. Zidan "Magnetic efects of the interfacial solitons in polystyrene composites," J . Phys D Appl Phys, vol. 23, pp. 1320-1323, August 1990.

7. P. K. Sahoo and P. K. Rana, "Synthesis and biodegradability of starch-methyl methacrylate/sodium acrylate/sodium silicate superabsorbent composite," J. Mater Sci, vol. 41, pp. 6470-6475, October 2006.

8. J. F. Zhang and X. Y. Sun, "Mechanical properties of poly (lactic acid)/starch composites compatibilized by maleic anhydride," J. Biomacromol, vol. 5, pp. 1446- 1451, May 2004.

9. D. R. Lu, C. M. Xiao, and S. J. Xu, "Starch-based completely biodegradable polymer materials," Express Polym. Lett., vol. 3, no. 6 , pp. 366-375, March 2009.

10. A. Pawlicka, A. C. Sabadini, E. Raphael and D. C. Dragunski, "Ionic Conductivity Thermogravimetry Measurements of Starch-Based Polymeric Electrolytes," J. Mol Cryst Liq Cryst, vol. 485, pp. 56-68, August 2008.

11. C. Liew and S. Ramesh, "Electrical, structural, thermal and electrochemical properties of corn starch-based biopolymer electrolytes," Carbohydr. Polym., vol. 124, pp. 222-228, June 2015.

12. C .-W. Liew, S. Ramesh, K. Ramesh and A. K. Arof, J. Solid State Electrochem, vol. 16, pp. 1869-187, 2012.

13. N. I. Harun, R. M. Ali, A. M. M. Ali and M. Z. A. Yahya "Conductivity studies on cellulose acetate-ammonium tetrafluoroborate based polymer electrolytes," J. Mater. Res. Innov., vol. 15 S168-72 , April 2011.

14. Rajendran S, Sivakumar M and Subadevib R, "Investigations on the effect of various plasticizers in PVA-PMMA solid polymer blend electrolytes," J. Mater. Lett, vol. 58, pp. 641-649, February 2004.

15. H. J. Woo, S. R. Majid and A. K. Arof, "Dielectric properties and morphology of polymer electrolyte based on poly( $\varepsilon$-caprolactone) and ammonium thiocyanate," J. Mater. Chem. Phys., vol. 134, pp 755-761, June 2012.

16. A. S. A. Khiar and A. K. Arof, "Conductivity studies of starch-based polymer electrolytes," J. Ionics, vol. 16, pp. 123-129, March 2010.

17. S. Ramesh and A. K. Arof, "Ionic conductivity studies of plasticized poly(vinyl chloride) polymer electrolytes," J. Mater. Sci. Eng. B, Vol. 85, pp. 11-15, August 2001.

18. J. Kawamura, N. Kuwata, R. Baskaran, S. Selvasekarapandian and T. Hattoriac, "AC impedance, DSC and FT-IR investigations on (x)PVAc- $(1-\mathrm{x}) \mathrm{PVdF}$ blends with LiClO4," J. Mater. Chem.Phys., vol. 98, pp. 55-61, July 2006.

19. D. Mangalaraj, K. Narayandass and K. Prabakar, "Dielectric and electric modulus properties of vacuum evaporated $\mathrm{Cd} 0.8 \mathrm{Zn} 0.2 \mathrm{Te}$ thin films," J. Mater.Sci.Eng.B., vol. 98, pp. 225, April 2003.

20. W. Dieterich and P. Maass, "Non-Debye relaxations in disordered ionic solids," J. Chem. Phys., vol. 284, pp. 439-467, November 2002.

\section{AUTHORS PROFILE}

M. Anandha Jothi is a Research scholar in the department of Physics, International Research Centre (IRC), Kalasalingam Academy of Research and Education, India. She has received B.Sc., and M.Sc., degree in Physics from Madurai Kamaraj University. She is doing research in the area of Solid Polymer Electrolytes for Electrochemical application.

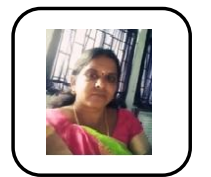

Dr. D.Vanitha is an Assistant Professor in the Department of Physics, School of Advanced Sciences at Kalasalingam Academy of Research and Education, India. She has obtained Ph.D. in the area of X-ray crystallography and Polymer Science from Kalasalingam Academy of Research and Education in 2016 and also received her M.Phil. and M.Sc. Degree in physics from Madurai Kamaraj University. She has expertise in the areas of Crystallography and Polymer Science. She has published more than ten peer-review research articles in journals of international repute besides ten more as proceedings.

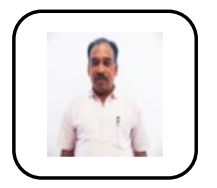

Dr. S. Asath Bahadur is a Senior Professor in the Department of Physics, School of Advanced Sciences at Kalasalingam Academy of Research and Education, India. He has obtained Ph.D. in the area of X-ray crystallography from Madurai Kamaraj University in 1994 and also received his M.Phil. and M.Sc. Degree in physics from Madurai Kamaraj University.He has expertise in the areas of Crystallography and Material science. He has published more than eighty-fivepeer-review research articles in journals of international repute besides seventy more as proceedings. 